\title{
A outra caixa de Pandora
}

\section{The other Pandora's box}

\author{
- lucrécta d’alessio FERRARA * \\ Pontifícia Universidade Católica de São Paulo, Programa de Pós-Graduação em Comunicação e \\ Semiótica. São Paulo - SP, Brasil
}

\section{RESUMO}

Como desenvolvimento de trabalhos anteriores, são estudadas as consequências culturais da tecnologia digital e o modo como interferem na comunicação ao desenvolver necessária e urgente distinção entre mediação e interação. Portanto, este trabalho tem como questão saber até que ponto a comunicação pode superar a dimensão linear da simples transmissão e ser sensível às transformações sociais contemporâneas que apontam para matrizes políticas da comunicação e a redefinem como área científica.

Palavras-chave: Comunicação, epistemologia, política, poder

\begin{abstract}
As a result of previous studies, this research aims to study the cultural consequences of digital technology and their interference on communication by developing a necessary and urgent distinction between mediation and interaction. Therefore, the subject of this study is to investigate to what extent communication can overcome the linear dimension of simple transmission and be sensitive to contemporary social transformations that allude to political roots of communication and redefine it as a scientific area. Keywords: Communication, epistemology, politics, power
\end{abstract}

\author{
* Professora titular \\ do Programa de \\ Pós-Graduação em \\ Comunicação e Semiótica \\ da Pontifícia Universidade \\ Católica de São Paulo \\ (PUCSP). Líder do Grupo \\ de Pesquisa Espaço \\ Comunicação Cultura \\ (ESPACC). Últimos \\ trabalhos publicados: \\ Comunicação, espaço, \\ cultura (São Paulo: \\ Annablume, 2008), Os \\ nomes da Comunicação \\ (São Paulo: Annablume, \\ 2012), Comunicação, \\ mediações, interações \\ (São Paulo: Paulus, 2015), \\ Cidade entre mediações \\ e interações (São Paulo: \\ Paulus, 2016). E-mail: \\ ldferrara@hotmail.com
}




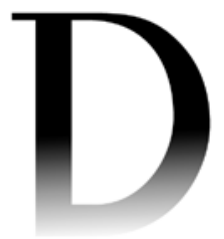

1. No original, "Tous les dieux, surl'ordre de Zeus, concoururent à la naissance de Pandore, la première femme: Je ferai présent aux hommes, dit Zeus, d'un mal em qui tous, au fond du coeur, se complairont à entourer d'amour leur propre malheur". Todos os trechos utilizados neste artigo foram traduzidos pela autora.

\section{A outra caixa de Pandora}

\section{Algumas epígrafes sugerem pensar:}

Sob as ordens de Júpiter, todos os deuses colaboraram para o nascimento de Pandora, a primeira mulher. Eu farei presente aos homens, diz Júpiter, de um mal com o qual todos, do fundo do coração, terão prazer ao envolver com amor, sua própria desgraça. (Laffont, 1969: 578) ${ }^{1}$

Todo aquele que reflete está interessado no espelho. O espelho é por definição um instrumento que reflete, que especula (de speculum = espelho).Não estamos mais tão interessados na face reflexiva do espelho. O nosso interesse está na outra face [...]. Estamos invertendo espelhos. Esta é uma das características da atualidade, espelhos invertidos [...]. Correm todos, creio, na região que se estende a partir da outra face do espelho. Isto nos distingue dos nossos antepassados. Estamos interessados na região atrás do espelho. Conosco começa uma nova época. A dos espelhos virados.

(Flusser, 1998: 67, 71)

O espetáculo que inverte o real é efetivamente um produto. Ao mesmo tempo, a realidade vivida é materialmente invadida pela contemplação

do espetáculo e retoma em si a ordem espetacular à qual adere de forma positiva. A realidade objetiva está presente dos dois lados. Assim estabelecida, cada noção só se fundamenta em sua passagem para o oposto: a realidade surge no espetáculo e o espetáculo é real. Essa alienação recíproca é a essência e a base da sociedade existente[...]. No mundo realmente invertido, a verdade é um momento do que é falso.

(Debord, 1997: 15-16)

\section{PANDORA HETEROTÓPICA}

A IMAGINAÇÃO JÁ não é desprezada, mas está sendo reabilitada 1 como irmã gêmea da razão, e surge como combustível da invenção, to dos mitos modernos. Os mitos alimentam a imaginação e abrem as portas do conhecimento para aquilo que é desconhecido, ou melhor, para a descoberta daquilo que surge como um horizonte de expectativas e conduz às origens escondidas da ação. Nas epígrafes que estimulam este trabalho, enfrentam-se traduções do mesmo mito que coloca os homens no centro de suas escolhas, porém, alienados, não lhes são mostradas as faces completas da escolha - ao 
contrário, elas lhes são escondidas como uma incógnita, um espelho virado. Essa é a pergunta que nos surpreende no mundo contemporâneo e à qual não podemos nos furtar, ainda que ela se nos apresente ambígua, virada.

Se o vocábulo meio (do latim medius) se refere àquilo que está no meio como exata metade de um todo ou ponto equidistante de dois extremos, o substantivo mediação (do latim mediatio, onis) recupera o sentido do primeiro vocábulo e lhe acrescenta outra vertente, atribuindo-lhe o caráter de intercessão destinada a produzir um acordo impelido à ação do mediar.

Nesse sentido e fiel às origens administrativas e funcionais da comunicação oficializada pelos meios técnicos e desenvolvida empiricamente no mundo moderno, mediação se refere ao sentido precípuo da comunicação entendida como aquilo que produz um efeito e, em função do qual, se administra e se expressa. Comunicação enquanto efeito planejado se ajusta à instância emissora e está pronta para reproduzir o efeito, que confirma o acordo previamente intencionado. Como em verdadeiro espelho, a comunicação se mostra por inteiro e reflete suas intenções de criar padrões ou opiniões, prontos para serem consumidos, repetidos, imitados. Midiatizado, esse efeito define a comunicação como espetáculo performático, criando uma espécie de homonímia entre a comunicação e seu efeito que transforma a relação entre os homens em alienação e, entre eles e a natureza, em utopia.

A palavra interação, ao contrário, exprime uma ação ou experiência que se dá em espaço intervalar do tempo; um acontecimento singular que ocorre em um espaço entre de um tempo interrompido (ou, mais propriamente, inacabado) que registra a singularidade da ação interativa da qual é parte constitutiva. Essa ação/experiência entre assinala uma articulação própria que, sem ser uma invariável do espaço ou do tempo em que se dá ou ocorre, os assinala pela emergência e atualização de uma singularidade múltipla.

Sem planos, intenções ou percursos determinados, a interação se opõe à mediação e, enquanto singularidade do tempo e do espaço, é uma experiência que assinala um processo comunicativo. Uma transformação que, naturalmente, em fluxo indeterminado, assinala a mudança daquele espaço/tempo entre no próprio momento em que ocorre. Aquelas ações podem construir uma rede de singularidades que encontra, no fluxo de seus nós (ou traços), os fios que lhes deram origem e que, embora entretecidos em rede, são igualmente singulares, próprios, intraduzíveis.

Um entre-lugar de espaço indeterminado e próximo daquilo que Foucault (2009) chamou de heterotopia ou heterotopologia de espaços absolutamente outros. Se, no território da comunicação, cabe à mediação o plano de seus efeitos planejados, à interação cabe criar a alteridade, sempre vaga e imprecisa, 
daqueles espaços e tempos heterotópicos, indeterminados. Entretanto, não nos iludamos: não se trata de criar entre mediações e interações a polaridade inócua e paradoxal de pares opostos, ao contrário, é necessário entender que entre mediações e interações surgem outros tempos e espaços que, heterocrônicos e heterotópicos, só podem ser compreendidos no compasso contínuo da mudança que se opera entre mediações e interações. O estudo desses tempos/espaços exige que sejam claramente contextualizados histórica e filosoficamente, a fim de que seja possível entender suas consequências para a comunicação contemporânea como área científica, na mudança, mais ou menos decisiva, entre mediação e interação.

\section{A MUDANÇA COMO ARTEFATO DA CAIXA DE PANDORA}

A interação ocorre como rede entretecida no espaço/tempo de suas singularidades, mas não se restringe a elas; ao contrário excede-as enquanto possibilidade contínua. Nesse sentido, embora marcada pelo espaço entre do instante em que ocorre, exige a atenção de um contínuo presente, sem passado e sem futuro: uma simultaneidade sem sequência. Uma ação carregada de intencionalidades sem planos ou efeitos prefixados, um espaço entre ações, um tempo entre intenções que o transformam, ao se transformarem, marcando frequentemente a história da humanidade. Uma caixa de Pandora.

A transformação decorre de ações que marcam uma mudança histórica e, nesse sentido, a interação é agente da transformação que ocorre em espaços entre, marcados pelo intervalo de sua ocorrência. É possível definir/precisar/ apreender exemplos dessa transformação interativa: as marcas dessa ação podem ser encontradas na passagem da cultura para a civilização ou na transformação da vida que se desloca do campo para a cidade. Sem detalhar a profusão de questões estudadas por Vilém Flusser, alguns temas devem ser destacados e, para os objetivos deste trabalho, relacionados. O primeiro tema se refere ao trânsito da civilização ocidental na passagem do mundo agrícola para o urbano ou da transformação da cultura nômade para a sedentária, do movimento de transformação do trabalho artesanal, para o tecnológico:

Cultura é produto da agricultura. É ela um "colher" (colere) das coisas arrancadas da natureza. Civilização é produto da vida urbana. É ela a tentativa de informar significativamente a vida do "cidadão" (civis). É formação, não colheita. (Flusser, 2007: 23)

Paralela a essa observação relativa à interação entre cultura e civilização, outra questão se refere à produção de conhecimento: 
As seguintes proposições podem ser comparadas: "Deus criou o mundo, a fim de que o homem possa viver nele", e "o mundo surgiu há 6 bilhões de anos em forma de Big Bang”. Ambas as proposições tratam do mesmo assunto, da origem do mundo, mas são respostas a perguntas diferentes. A primeira: "para que surgiu o mundo?" e a segunda "por que surgiu?" [...]. No início da história teriam sido colocadas questões que começam por "para que" e teriam sido seguidas de perguntas que começam com "por que" [...]. Segundo tal tese, a primeira proposição seria "explicação final" e a segunda "explicação programática". (Id., 1983: 41-42)

Esses dois exemplos nos mostram as mudanças do modo como entendemos a comunicação no eixo das transformações da humanidade: de um lado, as transformações culminaram com a passagem do estágio cultural agrícola para o civilizacional urbano; de outro, a ciência peregrinou entre as passagens de explicações funcionais dos fenômenos que respondem a indagações finais e as que, utilitárias, respondem a perguntas que exigem respostas definitivas, porque instrumentais. No momento da civilização tecnológica e da filosofia histórica em que nos encontramos, estamos diante de espelhos que nos parecem virados. Nessa encruzilhada, cabe-nos atentar para a necessidade de saber a forma como a ciência pode ocorrer.

Para entender o sentido dos dois exemplos, é necessário superar a emergência fenomenológica dos fatos recorrentes na cadeia de causas e fins: no caso da cultura, é necessário saber as consequências possíveis da passagem do mundo agrícola para a transformação urbana; no caso da ciência, para saber não as causas ou finalidades do conhecimento, mas o modo como ele pode intervir na civilização. Nos dois casos, é necessário superar a simples constatação fenomênica dos fatos para construir a história que se transforma em conhecimento e perceber os traços interativos que produzem possíveis respostas para as mudanças do mundo.

\section{A CAIXA DE PANDORA COMO AMEAÇA}

O mito grego de Pandora - que, ao abrir sua misteriosa caixa, seria responsável por espalhar, pelo mundo, dores e males - ressurge sempre que a humanidade se encontra diante de realidades que tendem a alterar profundamente seu futuro. A passagem do longo e sedentário mundo agrícola para o industrial constituiu motivo de tensão, pois deu lugar a profundas mudanças capazes de transformar a cultura ancestral em civilização e a competência manual em produção seriada e linha de montagem acionada pela máquina que, 
pouco a pouco, substituiu a força humana pela mecânica e a criatividade pela tecnologia do automático.

Nos séculos XVIII e XIX, a civilização foi testemunha da desastrada (ou esperançosa) abertura da caixa de Pandora, quando, acionada pela técnica e pela capacidade humana de transformar a máquina em modo de produzir riquezas, instalou-se decisiva mudança para a humanidade, que passava do mundo agrícola e artesanal para o industrial e capitalista. A década de 1960, com a primeira crise do petróleo, a decisiva assunção da classe burguesa como agente do capital, as negociações e pactos com a classe operária e os movimentos intelectuais inspirados em violenta crítica à cultura clássica, assinalou decisivo momento de inflexão a anunciar profunda mudança e inquietantes acontecimentos, a misteriosa caixa parece abrir-se outra vez fazendo novas ameaças e promessas. A concentração de três quartos da população mundial vivendo em cidades surge como ameaça de deficit inalienável de habitação, alimento, cultura e bem-estar, entretanto essa ameaça de mudança aponta para um dado concreto: não é dado ao homem deliberar sobre tudo e, através de planos, mais ou menos racionais, definir posições e controles para a humanidade e para as máquinas que eles próprios conceberam. Hoje as máquinas e os homens convivem, e, para essa relação, é necessário rever ou construir as associações sociais: o século XXI feito de homens e máquinas é um só e, como tal, exige ser operacionalizado e estudado. Se o meio técnico, transformado em política de poder, constituiu o grande débito dos séculos XIX e XX e uma ameaça para a humanidade que a ele se submeteu, assumir e enfrentar essa realidade é o desafio deste século e a promessa de abertura de outra caixa de Pandora.

\section{A EPISTEMOLOGIA DA COMUNICAÇÃO COMO CAIXA DE PANDORA}

Na passagem do século XX para o XXI, o processo comunicativo apareceu em definitiva aceleração e caracterizou um mundo que surgiu como novo tempo explosivo de possibilidades montadas sobre a teia de relações de um sistema aberto. Segundo Lazzarato (2006: 39), "Nosso tempo é o da explosão desses diferentes mundos que vêm se atualizar, o que nos leva a uma outra ideia da política, da economia, da vida e do conflito”. Essa emergência de mundos possíveis atualizados pela contemporaneidade faz da comunicação um processo que marca o cotidiano, ou seja, não nos comunicamos, estamos em comunicabilidade que aparece como acontecimento contemporâneo. 
Uma antiga categoria de análise, proposta por Foucault (2011: 57-58) na célebre aula proferida no Collège de France em 2 de dezembro de 1970, assim define o acontecimento:

Certamente o acontecimento não é nem substância nem acidente, nem qualidade, nem processo; o acontecimento não é da ordem dos corpos. Entretanto, ele não é imaterial; é sempre no âmbito da materialidade que ele se efetiva, que é efeito; ele possui seu lugar e consiste na relação, coexistência, dispersão, recorte, acumulação, seleção de elementos materiais; não é o ato nem a propriedade de um corpo; produz-se como efeito de e em uma dispersão material. Digamos que a filosofia do acontecimento deveria avançar na direção paradoxal, à primeira vista, de um materialismo do incorporal.

Evoluindo nas inferências permitidas pela definição anterior, o renomado conceito vem sendo transformado em modo de percepção do contemporâneo. É tema que emerge em trabalhos de vários estudiosos que, ao analisarem o contemporâneo, o fazem sob a égide do acontecimento cuja definição faz jus à complexidade do mundo que o hospeda. Além dos próprios e distintos caminhos através dos quais é possível atingir o conceito de acontecimento, ele sugere que o entendamos na atmosfera do contemporâneo que, por sua vez, também exige ser rastreado em suas possibilidades de entendimento.

Ao definir o contemporâneo, Agamben (2009: 57) é radical na exigência de que a compreensão daquela categoria nos faz "contemporâneo(s) aos textos e aos autores que se examinam. Tanto o seu grau quanto o seu êxito serão medidos pela sua - pela nossa - capacidade de estar à altura dessa exigência". Ou seja, entender o tempo contemporâneo exige que sejamos participantes de sua vida e de sua complexidade social, cultural e tecnológica, mas sem estar com elas envolvidos ou ser a elas submissos. Para entender o contemporâneo, é necessário ser heterotópico, a fim de manter um olhar livre e dissociado, capaz de ver além do tempo que surge como simples cronologia da aceleração:

A contemporaneidade, portanto, é uma singular relação com o próprio tempo, que adere a este e, ao mesmo tempo, dele toma distâncias; mais precisamente, essa é a relação como o tempo que a este adere através de uma dissociação e um anacronismo. Aqueles que coincidem muito plenamente com a época ou que, em todos os aspectos, a esta aderem perfeitamente, não são contemporâneos porque, exatamente por isso, não conseguem vê-la, não podem manter fixo o olhar sobre ela. (Ibid.: 59) 


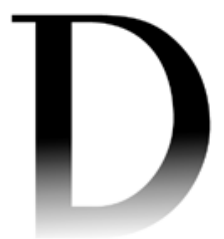

2. No original, "Una vida sólo contiene entidades virtuales. Está hecha de virtualidades, acontecimientos, singularidades. Lo que se denomina virtual no es algo que carece de realidade sino que, siguiendo el plan que le da supropria realidade, se compromete em un processo de actualización.

El acontecimento inmanente se actualiza em un estado de cosas y em un estado vivido que hace que ocurra $[\ldots]$. Los acontecimientos o singularidades le dan al plano toda sua virtualidade, así como el plano de inmanenciale da a los acontecimentos virtuales una realidad plena”.

Ao lado do conceito de contemporâneo, o acontecimento assume dimensões que, no nosso tempo, constituem a chave da possibilidade de entender o conceito - porém, não no sentido de lhe decifrar um significado, mas de propor acontecimentalizações que se inscrevem, no âmago do acontecimento, como compreensões, inteligibilidades apenas possíveis e jamais necessárias ou definitivas. Deleuze (2009) também se dedicou à tarefa de definir, a partir de Foucault, o acontecimento, dando-lhe dimensões ambiciosas de análise filosófica , mas contemporâneas, ao exigir que o entendamos na ambivalência daquilo que é imanente e virtual ao mesmo tempo. Isso parece querer dizer que o contemporâneo é aquele tempo que não se deixa narrar, pois sua história não apresenta teleologias narrativas, ao contrário, nele tudo está à espera de um acontecimento que o atualize de modo evidente, mas com a duração de um dígito:

Uma vida só contém entidades virtuais. Está cheia de virtualidades, acontecimentos, singularidades. O que se denomina virtual não é algo que careça de realidade, mas ao contrário acompanhando o plano de sua própria realidade, se compromete com um processo de atualização. $\mathrm{O}$ acontecimento imanente se atualiza em um estado de coisas e em um estado vivido que o faz ocorrer [...]. Os acontecimentos ou singularidades dão ao plano toda sua virtualidade, assim como o plano de imanência dá aos acontecimentos virtuais uma realidade plena. (Ibid.: 40$)^{2}$

O confronto entre os conceitos de Foucault e Deleuze, associados ao contemporâneo de Agamben, nos leva a observar que nos encontramos na mesma teia de relações que, em seus nós ou rastros, se apresentam como cerne da complexidade dos fenômenos que caracterizam o mundo atual e, nele, a comunicação e sua epistemologia que, enoveladas entre mediações e interações, exigem indispensável aproximação entre a história e a filosofia.

Considerando que a comunicação se submete, em sua produção e divulgação, aos controles de dispositivos mediativos espetaculares e, quase nunca, interativos, é necessário desenvolver outra reflexão: a dimensão política daquela realidade epistemológica pode surgir como outro lugar, uma heterotopia cognitiva ou um acontecimento que, no contemporâneo, subverte teorias, métodos fixados ou temas de estudo apoiados na mediação espetacular, para fazer acontecer a imprevista interação que pode decorrer, mas não necessariamente, de suportes tecnológicos e se faz observar por suas consequências sociais e culturais, como desde os anos 1960 já afirmava McLuhan (1969: 21-22).

Se a mediação constitui instrumento útil para atingir um receptor, entendido como massa ou público dócil à política que utiliza a comunicação como 
instrumento, a interação, ao contrário, propõe uma atividade relacional que exige observar a natureza política da comunicação enquanto área científica e questiona até que ponto a comunicação pode superar a dimensão linear da simples transmissão ou os dispositivos midiáticos que a caracterizam como instrumento de poder, para ser sensível às transformações sociais da atualidade, que exige outra epistemologia atenta às consequências políticas que a própria ciência desenvolve. Produz-se, portanto uma política da comunicação, mas não aquela que faz das condições mediativas cenário adequado para seus interesses: opõem-se, portanto, a política da comunicação e aquela que ocorre na comunicação. É urgente saber como definir as dimensões que caracterizam a comunicação e suas decorrências conceituais quando estas se voltam para as matrizes políticas da própria comunicação e, radicalmente, a redefinem como interação inserindo, em sua epistemologia, outras esferas de estudo e investigação (Ferrara, 2015: 11).

Portanto, a interação nos leva a considerar que a política epistemológica da comunicação não considera a política que, espetacular enquanto imagem e mensagem, se faz insistente como mediação interesseira a serviço de estratégias e dispositivos de poder. Ao contrário, uma epistemologia da comunicação interativa pode se propor à construção de uma política que permite, à comunicação, rever seu objeto científico e seu exercício pragmático em constante processo de consecução. Somos levados a ceder à evidência de que cabe à comunicação considerar não a ciência que se quer - porque confortável enquanto aplicação de teorias e métodos determinados como válidos cientificamente -, mas observar que a epistemologia de uma comunicação está voltada para a apreensão do exercício ininterrupto e contemporâneo que ocorre entre mentes e ideias.

Essa epistemologia exige considerar a política como seu elemento constitutivo porque propõe outro modo de fazer comunicação como exercício, não apenas científico, mas como cotidiano comunicante que é a arquitetura de uma ciência, talvez menos segura, mas certamente mais instigante. Exige-se atenção epistemológica para apreender o ambiente social e cultural produzido como consequência das habilidades dos meios tecnológicos - mas não só digitais -, a fim de que nos habilitemos a surpreender ou sermos surpreendidos por uma realidade ambiental em que tudo se comunica e nos afeta, criando outra ecologia mental para a qual nada está pronto para ser usado e aplicado, mas tudo está disponível para aquela atenção que, alerta, está em comunicação.

A diferença entre a empiria de mediações e interações se encontra, no primeiro caso, em forte apelo fenomenológico que se impõe pela própria natureza comunicativa transmissiva e constitui a principal manifestação das mediações. 
No segundo caso, e também considerando aquela natureza empírica, as manifestações interativas exigem uma atenção arqueológica, não para buscar a origem inesgotável das interações, mas os traços que, quase ocultos, se encontram naquelas manifestações e permitem imaginar que o discurso que as expressa não tem enunciados discrimináveis, ao contrário são formações discursivas que, históricas, não se enunciam pela ação de um sujeito-emissor, mas apresentam anteriores ocorrências, nem sempre claramente apreensíveis, mas que podem ser percebidas em outros acontecimentos. Ou seja, na formação discursiva de uma interação, a comunicação evidencia alguns textos verbais ou não, enquanto outros se escondem em breves e inusitadas fissuras que os ocultam, mas não os apagam. Exige-se, portanto, descobrir a história que vai além de simples eventos e a comunicação que se constrói além da mensagem.

Quando Foucault (1966) propõe liberar a episteme dos simples enunciados de manifestações quase sempre de base antropocêntrica, para aderir a uma arqueologia que não procura encontrar, na história, a espetacularidade de seus eventos, mas os acontecimentos que, reiterativos, parecem constituir a imanência da própria vida, deixa evidente que é necessário encontrar, nos traços que se escondem sob as interações, as formações discursivas que constituem sua base. Ao contrário, do ponto de vista fenomenológico, é possível distinguir, nas mediações, a submissão política da comunicação aos dispositivos tecnológicos (Agamben, 2009) e seus inequívocos interesses midiáticos que, surgindo como instrumentos a serviço do capital e do poder, tornam impossível a interação e o próprio exercício do acontecimento comunicativo.

Uma epistemologia política da comunicação supõe considerar: a) três evidências: as diferenças entre mediação e interação, a antitransmissibilidade da mensagem, a ecologia ambiental das mentes em comunicação; b) três descompassos: a definição estável do objeto científico, a superação do método que vai além da metodologia proposta como um a priori, a atenta indeterminação da ocorrência comunicativa que surge como fantasma da certeza científica; c) três promessas: a emergência de outro modo de pesquisar e entender a comunicação, a comunicação como ação social e política radical, sua possibilidade de construção histórica.

\section{AS PROMESSAS DA OUTRA CAIXA DE PANDORA}

Sob a influência das associações de resistência entre conexões estudadas por Bruno Latour (2006) na proposta do conceito de ator-rede, apresenta-se um processo empírico disposto a perceber ambivalências e a não reduzir a comunicação ao padrão de uma simples mediação técnica. Nesse ambiente, 
aproximam-se a produção do conhecimento e a própria definição da comunicação como área científica.

Se na realidade contemporânea são constantes, de um lado, as constatações da comunicação como dispositivo de poder, de outro é possível apreender, através daqueles mesmos dispositivos de natureza tecnológica fixa e/ou móvel, um potencial associativo de inusitadas proporções que, paradoxalmente, coloca em cena e evidência o poder como realidade política que se transmite e se impõe, através de suas dimensões comunicativas midiáticas.

Entretanto, aquela evidência estimula possibilidades de resistências que, aparentemente frágeis, espontâneas e banais, sugerem sutis distinções entre a comunicação que se divulga e aquela que se faz e se constrói no cotidiano que agasalha a comunicabilidade e constrói a resistência radical de associações consideradas, atualmente, como outra categoria de análise do social com profundas consequências comunicativas (Latour, 2006; Lazzaratto, 2006; Laclau; Mouffe, 2010).

No exercício de associações distantes das práticas da comunicação oficial, salienta-se a endógena e indiscutível dimensão político-interativa da comunicação feita de resistência que, de forma viral, ocorre entrementes e corpos em contínua reflexão e procuram construir um ambiente comum que não se detém na comunicação midiática, mas se permite o poder de transformá-la e inserir outros capítulos à ciência que a estrutura, em um século que promete tornar-se celeiro de acontecimentos.

Nesse contemporâneo, surge a inevitável crise da representação que se comunica e nos faz observar que estão virados os espelhos em que nos refletíamos e conhecíamos, porque submissos a uma comunicação que se espelhava em seus efeitos. Está virado aquele espelho que refletia a técnica produtiva e reprodutiva que se desenvolveu de modo mais incisivo a partir de segunda metade do século XX. Emerge a imagem persuasiva de uma sociedade de espetáculo, cada vez mais alienada - das consequências culturais de sua ação - e alienadora, porque saturada pela redução ao simples entretenimento. Considerando que a década de 1960, sobretudo a partir dos eventos de 1968, constituiu um momento de inflexão que marca a definitiva tentativa de superação do movimento modernista e suas consequências ideológicas, sociais, econômicas e políticas, para atingir a modernidade, observa-se que a comunicação que se faz e a que se estuda começa a perceber a necessidade de alterar suas bases de programação e, sobretudo, sua epistemologia: inicia-se a longa e exaustiva reflexão que exige reconsiderar o objeto científico da comunicação. Aquele antigo objeto de entretenimento alienado e alienante dos meios de massa é substituído por uma relação comunicante vaga, mas não vazia, porque se coloca como dife- 


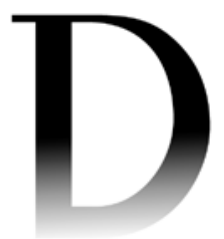

3. No original, "One should not conceive of the city to be designed as a geographical place (such as a hill near a river), but rather as a fold in the intersubjective relational field. This is what is meant by the assertion that the future civilization must become 'immaterial"'.

\section{A outra caixa de Pandora}

rença que inaugura um comunicar que, comum e cotidiano, é apenas possível. Abre-se, para a epistemologia da comunicação, outro território, onde já não se pergunta o que é ou para que ela serve, mas como e quando acontece a comunicação que não se convalida por seus efeitos, mas pelos múltiplos e imprecisos modos de sua ocorrência.

A história é relida além de sua duração breve ou longa porque, superando o tempo, é assumida sem surpresas e se situa na dinâmica dos acontecimentos que ocorrem em processo contínuo e sem tempo. Emergem noções fundamentais para a história atual: "não mais o tempo e o passado, mas a mudança e o acontecimento" (Foucault apud Dosse, 2013: 159), que ocorrem em novos lugares comunicativos, sem geografia e sem territórios, como observa Flusser (2002: 177):

Não se pode conceber que a cidade seja designada como um espaço físico (como uma montanha perto de um rio), mas de preferência como uma dobra intersubjetiva em um campo relacional. É isso que se quer dizer com a asserção que afirma que a futura civilização deve tornar-se "imaterial".

Sob o impacto da mudança, a ordem sequencial é definitivamente rompida, de sorte que não há como procurar causalidades ou progressões explicativas. Essa mudança não é prevista ou planejada, mas, acompanhando o acontecimento, é da ordem do descontínuo, pois

não se trata nem da sucessão de instantes do tempo, nem da pluralidade dos diversos sujeitos pensantes; trata-se de cesuras que rompem o instante e dispersam o sujeito em uma pluralidade de posições e de funções possíveis. Tal descontinuidade golpeia e invalida as menores unidades tradicionalmente reconhecidas ou as mais facilmente contestadas: o instante e o sujeito. (Foucault, 2011: 58)

Corroborando e intensificando a posição anterior, Lazzarato (2006: 32-33) amplia o sentido da mudança para os modos de viver e de sentir, e faz daquele descontínuo do acontecimento uma forma de compreensão do mundo predisposto à mudança e à transformação:

Um mundo é uma multiplicidade de relações que não dependem de uma essência, mas de um acontecimento. As relações pressupõem o acontecimento que age transformando o sentir, ou seja, os desejos, as crenças, os afetos [...]. A expressão e a constituição de maneiras de sentir, em vez de depender do modo de produção, 
são anteriores ao funcionamento da economia [...] é a partir da cooperação que podemos pensar uma economia dos afetos, uma economia do sensível.

Essa nova economia (ou esse outro modo de produção) propõe, do ponto de vista epistemológico, diferente papel político para a ciência e para a ação do pesquisador:

O papel do intelectual não é mais o de se posicionar "um pouco à frente e um pouco ao lado" para dizer a verdade muda de todos: é antes o de lutar contra as formas de poder ali onde ele é, ao mesmo tempo, o objeto e o instrumento disso: na ordem do "saber", da "verdade", da "consciência", do "discurso". É nisso que a teoria não expressará, não traduzirá, não aplicará uma prática, ela é uma prática [...] não totalizadora. (Foucault, 2010: 39)

Nesse cenário, surge o comunicar que anuncia a política feita de ausência de mensagens pressupostas, a fim de que seja possível considerar o modo do acontecer que, disperso no cotidiano, surge como possibilidade de ação entre os homens. Nesse sentido, uma epistemologia política da comunicação também estaria atenta aos efeitos, porém, não àquele plano que transforma os meios técnicos em seus instrumentos, mas ao modo imprevisto como a comunicação - tecnológica ou não - pode ocorrer. Uma epistemologia que considere com atenção o comunicar será surpreendida por corpos e mentes em comunicabilidade que, sem pressupostos, fazem da comunicação um agente de mudança do mundo; estamos ante outra caixa de Pandora que, agora, já não distribui males ou benesses, mas se abre como exigente insinuação de mudanças e ações.

Nas promessas do século XXI, impõe-se considerar que, perante um tempo assinalado por decisiva crise da representação, os meios técnicos já não constituem espelhos nos quais somos refletidos, dispostos à imitação de seus modelos. Diante dos espelhos virados, abre-se, outra vez, a misteriosa caixa de Pandora, e é possível perceber que a comunicação não é o modelo perante o qual nos colocamos alienados, mas é preciso entender o comunicar que, disperso e frágil, surge como promessa de outra imagem do homem para os homens. Essa é a construção antiespecular e política do nosso século. M

\section{REFERÊNCIAS}

AGAMBEN, G. O que é o contemporâneo e outros ensaios. Chapecó: Argos, 2009.

DEBORD, G. Sociedade do espetáculo. Rio de Janeiro: Contraponto, 1997. 
DELEUZE, G. La inmanencia: una vida... In: GIORGI, G.; RODRÍGUEZ, F. Ensayos sobre biopolítica: excesos de vida. Buenos Aires: Paidós, 2009. p. 35-40.

DOSSE, F. Renascimento do acontecimento. São Paulo: Unesp, 2013.

FERRARA, L. D'A. Comunicação, mediações, interações. São Paulo: Paulus, 2015.

FLUSSER, V. Pós-história: vinte instantâneos e um modo de usar. São Paulo: Duas Cidades, 1983. . Ficções filosóficas. São Paulo: Edusp, 1998. . Writings. Minneapolis: University of Minnesota Press, 2002. . Bodenlos: uma autobiografia filosófica. São Paulo: Annablume, 2007.

FOUCAULT, M. Les mots et les choses. Paris: Gallimard, 1966. . Ditos e escritos IV: estratégia poder-saber. Rio de Janeiro: Forense Universitária, 2010.

. A ordem do discurso. 21. ed. São Paulo: Loyola, 2011. O corpo utópico, as heterotopias. São Paulo: N-1Publications, 2013. Edição bilíngue.

LACLAU, E.; MOUFFE, C. Hegemonía y estratégia socialista: hacia uma radicalización de la democracia. Buenos Aires: Fondo de Cultura Económica, 2010.

LAFFONT, P. Dictionnaire des symboles. Paris: Jupiter, 1969.

LATOUR, B. Changer de société, refaire de la sociologie. Paris: La Découverte, 2006.

LAZZARATO, M. As revoluções do capitalismo. Rio de Janeiro: Civilização Brasileira, 2006.

MCLUHAN, M. Os meios de comunicação como extensões do homem. São Paulo: Cultrix, 1969.

Artigo recebido em 19 de outubro de 2015 e aprovado em 21 de junho de 2016. 